Open Access

\title{
The detail of the en bloc technique and prognosis of spleen-preserving laparoscopic distal pancreatectomy for pancreatic cancer
}

\author{
Zhipeng Sun ${ }^{\dagger}$, Yubing Zhu ${ }^{\dagger}$ and Nengwei Zhang ${ }^{*}$
}

\begin{abstract}
Background: Although laparoscopic spleen-preserving distal pancreatectomy surgery is more and more popular, the reports about the en bloc technique used for pancreatic cancer were still rare. The aim of our study was to illustrate the detail of the spleen-preserving en bloc technique as well as the short-term and long-term outcomes.

Methods: The detail of the en bloc technique with pictures was described. The prognosis of the successive 23 cases that underwent the laparoscopic distal pancreatectomy (LDP) surgery was evaluated.

Results: There were 17 cases that underwent spleen-preserving LDP while six cases underwent spleen-resecting LDP. The average surgery time was $203 \pm 54 \mathrm{~min}$, and the average blood loss volume was $208 \pm 264 \mathrm{ml}$; one case transferred to open surgery because of severe adhesion. The complication rate was $47 \%(n=8)$ shortly after surgery. Pancreatic fistula rate was $41 \%(n=7)$. No lethal case occurred. The average diameter of the tumor was $32 \pm 12 \mathrm{~mm}$. The average number of the lymph nodes obtained was $19.8 \pm 9.3$. All the cutting edges were negative. Survival rates of the patient after 1,3, and 5 years are $64.7,52.9$, and $41.2 \%$, respectively. These records showed no statistical significance compared with spleen-resecting LDP and open distal pancreatectomy (ODP) surgeries.
\end{abstract}

Conclusions: The en bloc spleen-preserving LDP can be performed by experienced surgeons. This surgery has good short-term and long-term outcomes.

Keywords: Spleen-preserving, Laparoscopic distal pancreatectomy, Pancreatic cancer

\section{Background}

In the past 20 years, laparoscopic pancreatectomy surgery has been recognized and performed gradually from diagnostic laparoscopic exploration, specimen biopsy to distal pancreatectomy, and pancreatoduodenectomy [1]. Because the procedure of laparoscopic distal pancreatectomy (LDP) was not very complex, the number of cases that underwent this surgery raised quickly for benign and low-grade malignant disease [2].

\footnotetext{
* Correspondence: zhangnw1@sohu.com

${ }^{\dagger}$ Equal contributors

Oncology Surgery Department, Peking University Ninth School of Clinical Medicine (Beijing Shijitan Hospital, Capital Medical University), 334room, Administrative Building, Beijing, China
}

Although there were many articles about laparoscopic distal pancreatectomy reported [3], the en bloc concept was rarely mentioned. Many procedures reported [4] only contain the distal pancreatectomy technique excluding the ganglion resection, lymph node resection, Gerota fascia removal, and Toldt fascia removal. These procedures were not suitable for pancreatic cancer.

Depending on the Japanese General Rules for the Study of Pancreatic Cancer [5], we designed an en bloc spleen-preserving LDP procedure which removes the Gerota fascia, the Toldt fascia, and the distal pancreas as a whole and resects the 1st and 2nd station lymph nodes (Table 1). Spleen-preserving LDP against pancreatic

\section{() Biomed Central}

(c) 2015 Sun et al. Open Access This article is distributed under the terms of the Creative Commons Attribution 4.0 International License (http://creativecommons.org/licenses/by/4.0/), which permits unrestricted use, distribution, and reproduction in any medium, provided you give appropriate credit to the original author(s) and the source, provide a link to the Creative Commons license, and indicate if changes were made. The Creative Commons Public Domain Dedication waiver (http://creativecommons.org/publicdomain/zero/1.0/) applies to the data made available in this article, unless otherwise stated. 
Table 1 Pancreatic lymph node group in the General Rules for the Study of Pancreatic Cancer

\begin{tabular}{ll}
\hline & Pancreatic tail \\
\hline 1st group & $8 \mathrm{a}, 8 \mathrm{p}, 10,11 \mathrm{p}, 11 \mathrm{~d}, 18$ \\
2nd group & $7,9,14 \mathrm{p}, 14 \mathrm{~d}, 15$ \\
3rd group & $5,6,12 \mathrm{a}, 12 \mathrm{~b}, 12 \mathrm{p}, 13 \mathrm{a}, 13 \mathrm{~b}, 17 \mathrm{a}, 17 \mathrm{~b}, 16 \mathrm{a} 2,16 \mathrm{~b} 1$ \\
\hline
\end{tabular}

cancer may be still controversial, and until now, there has not been any report from a single center about the long-term prognosis and the standard en bloc LDP procedure of the surgery. Our aim is to describe the detail of the standard en bloc technique and to evaluate the short-term and long-term prognoses compared with the previous studies [6-10] about open distal pancreatectomy (ODP).

\section{Methods}

From the year 2007 to 2010, there were 60 patients who underwent distal pancreatectomy (DP) surgery. Among them, 45 cases underwent LDP surgery, 15 cases underwent ODP surgery, and 23 cases had pancreatic cancer in the LDP surgery group. Before the year 2002, the indications of LDP were benign diseases. After 2002, LDP was indicated both in benign and malignant diseases. All the patients' medical records and pathology results were reviewed.

\section{Ethics, consents, and permissions}

The demerits of LDP against pancreatic cancer were the high requirements of surgical skills and the uncertain outcomes. The merits of LDP were the micro-invasive effects leading to fast recovery.

This retrospective study was approved by the Peking University Ninth School of Clinical Medicine ethics committee. Patient records were de-identified prior to analysis. All the patients signed informed consents before surgery.

\section{The surgical procedure of en bloc LDP}

We have three principles in the concept of en bloc spleen-preserving LDP surgery. First is to dissect from the Gerota fascia to the Toldt fascia exposing the left kidney, left renal vein, left adrenal vessels, and left adrenal gland. The en bloc technique dissects the Gerota fascia, Toldt fascia, and distal pancreas. Second is to dissect the lymph nodes and ganglions along the celiac trunks while resecting the lymph nodes and ganglions along the superior mesentery artery (SMA). Third is, if the spleen and the left gastro-epiploic vessels were not invaded, to dissect the spleen vessels but preserve the spleen.
The detail of the technique is depicted as follows (Fig. 1).

The patient was placed in a lithotomic position. We inserted $10-\mathrm{mm}$ trocars in the umbilicus and right midclavicle line below the costal margin separately, and double 5-mm trocars in the left upper quadrant of the abdomen. After dissecting the greater omentum, we divided the mesocolon transversum from the Gerota fascia. Then, we identified the inferior border of the pancreas.

We dissected from the Gerota fascia to the Toldt fascia exposing the left kidney, left renal vein, left adrenal gland, and inferior mesenteric vein (IMV) with the en bloc method from lateral to medial. We retracted the pancreas from the dorsal side to the ventral side. We exposed the junction of the spleen vein and superior mesentery vein (SMV) from the dorsal side of the pancreas. We mobilized the SMA and resected the lymph nodes and celiac ganglion group II at the left side of the SMA.

We dissected the parenchyma of the pancreas at the root of the spleen vein. After that, we ligated the spleen vein and spleen artery at the root. We continued to resect the lymph nodes and celiac ganglion group II at the left side of the SMA. We preserved the right half of the celiac ganglion group II at this place. We dissected the adipose tissue upward to the cephalic side. We exposed the celiac trunk and resected the lymph nodes and celiac ganglion group I at root of the celiac trunk. We preserved the right half of the celiac ganglion I. Then, we moved to the left. We skeletonized the left adrenal gland and resected the adipose tissue and lymph nodes around it.

Finally, at the tail of the pancreas, we ligated and dissected the spleen vessels and preserved the gastroepiploic vessels and short gastric vessels.

After this procedure, the common hepatic artery, left gastric artery, celiac trunk, SMA, left adrenal gland and its vessels, left kidney, and left renal vein are exposed. The en bloc distal pancreatectomy is finished (Figs. 2 and 3). At last, we closed the pancreatic duct, dislodged the specimen, and left a drainage tube at the surgical region.

\section{Data collection and statistical analysis}

To analyze the complications after surgery, we adopt the Clavien-Dindo classification method [11]. To analyze the pancreatic fistula, we adopt the International Study Group of Pancreatic Fistula classification method [12]. The definition of spleen infarction was that the regional or total spleen is not enhanced by contrastenhanced CT. The criteria of discharge were that the complications of the patient were stabilized, no analgesia was taken, and the patient could accomplish 

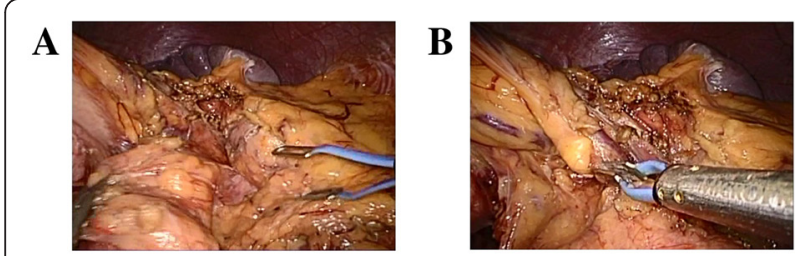

C
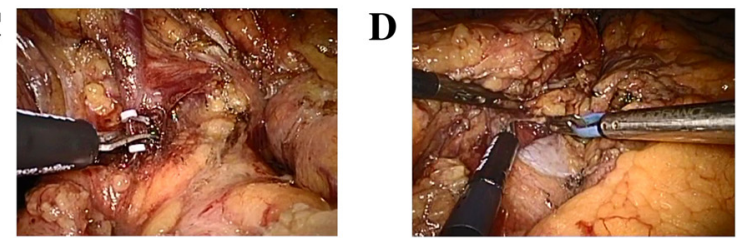

$\mathbf{E}$

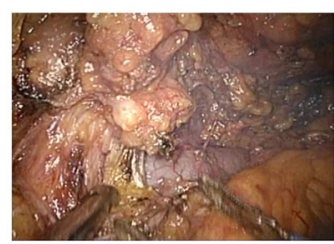

F

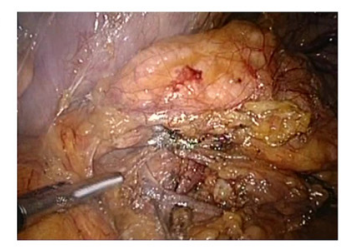

G

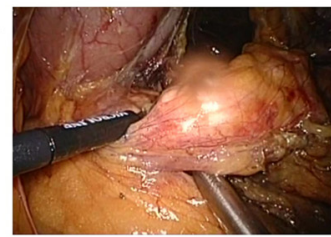

$\mathbf{H}$

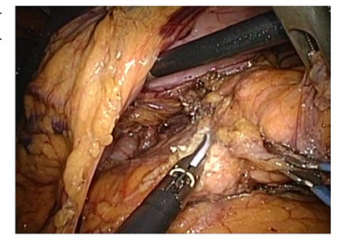

I

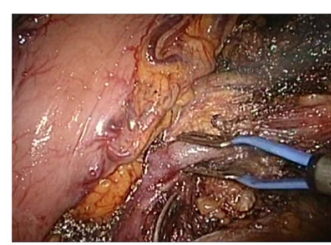

$\mathbf{K}$

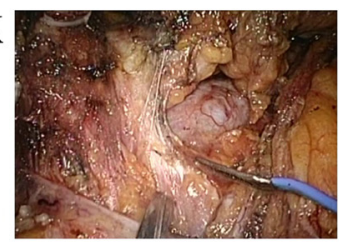

M

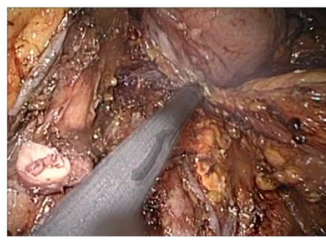

$\mathbf{O}$

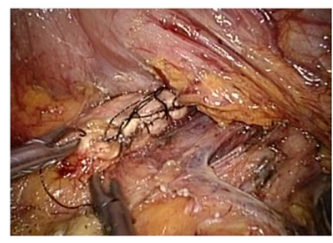

$\mathbf{J}$

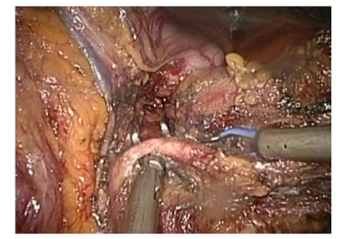

$\mathbf{L}$

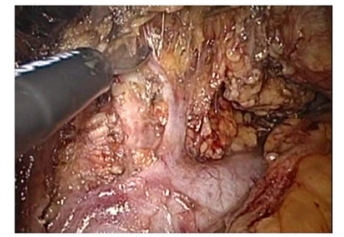

$\mathbf{N}$

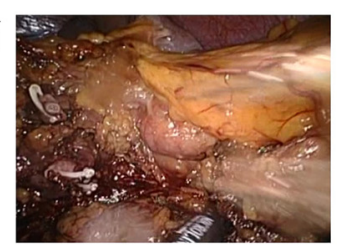

$\mathbf{P}$

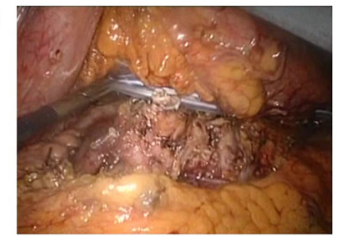

Fig. 1 The technique of standard en bloc spleen-preserving LDP. a Dissect the gastro-colic ligament and disconnect the transverse mesocolon from the Gerota fascia. b At the level above the upper surface of the pancreas, isolate the left gastro-epiploic vein (LGEV) and the communicating veins from the distal pancreas. Preserve the LGEV. c Dissect between the communicating vessels and the distal pancreas. $\mathbf{d}$ At the tail of the pancreas, dissect the Gerota fascia from the lower border of the left renal vein upward to the left kidney. e Continue to dissect the Gerota fascia to the left border of the superior mesentery artery (SMA). Dissect the lymph nodes and celiac ganglion group II around the SMA preserving the 5-mm ganglion at the right side. $\mathbf{f}$ Continue to dissect upward to the splenic vein. Expose the splenic vein and IMV and ligate and cut off the IMV. $\mathbf{g}$ Penetrate the pancreas from the posterior surface at the root of the splenic vessels. $\mathbf{h}$ Dissect the pancreas at the root of the splenic vessels with a Harmonic scalpel. i Isolate the splenic vein at the root and dissect it. $\mathbf{j}$ Isolate the splenic artery at the root and dissect it. $\mathbf{k}$ Dissect the lymph nodes and celiac ganglion group I around the celiac trunk preserving the 5-mm ganglion at the right side. I Dissect the retroperitoneum adipose tissue at the upper border of the pancreas. Expose the left adrenal vessels and adrenal gland. $\mathbf{m}$ Preserve the adrenal gland if it has not been invaded. Dissect the retroperitoneum adipose tissue to the origin. $\mathbf{n}$ Ligate and dissect the spleen vessels at the tail of the pancreas. $\mathbf{o}$ Invertedly suture the stump of the pancreas. $\mathbf{p}$ Leave a drainage tube in the surgical site

daily activity. The follow-up items after discharge included routine test, tumor markers (CEA, CA199), contrast-enhanced CT, or MRI according to the NCCN guideline [13].

\section{Statistical analysis}

Categorical variables were demonstrated as quantity or percentage. To compare between groups, we use Fisher's test or chi-square. Successive variables were demonstrated as mean \pm SD. To compare them, we use $t$ test. Survival duration started from the date of the surgery. Recurrence-free survival curve was depicted by the Kaplan-Meier method. When we evaluated the recurrence-free survival time, we included the recurrence-free lethal cases. SPSS (version 19.0.2; SAS Institute Inc., Cary, NC) software was used in the statistical analysis.

\section{Results}

Among the 23 pancreatic cancer patients who underwent LDP, 12 were males and 11 were females. Average age was $65 \pm 11.4$ years. Average BMI was $25.9 \pm 4.4 \mathrm{~kg} / \mathrm{m}^{2}$. Anesthesia risk score (ASA score) was 2.2. No patients underwent neo-chemotherapy before surgery. The information during the surgery was depicted in Table 2. There are 17 spleen-preserving LDP cases and six spleen-resecting LDP cases. Average surgery time was $203 \pm 54 \mathrm{~min}$. Average blood loss was $208 \pm 264 \mathrm{ml}$. One case converted to ODP because of severe 

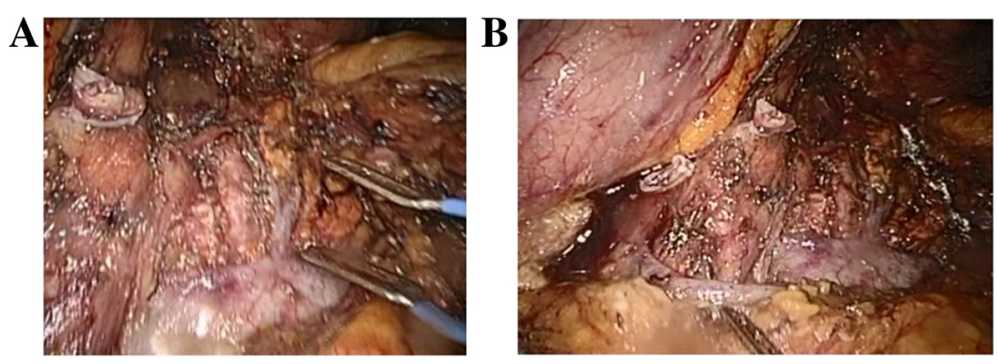

Fig. 2 The posterior peritoneal structure after dislodging the specimen. a. The stump of the spleen artery, left renal vein, left adrenal vessels, and SMA was shown in the picture after surgery. $\mathbf{b}$ The stump of the spleen vein was shown in the picture

adhesion between the greater omentum, transverse colon, and intestine. There was no statistical significance in surgery time between the spleen-preserving LDP group and the spleen-resecting LDP group (198 \pm 59 vs $223 \pm 29 \mathrm{~min} ; P=0.45)$. There was no statistical significance in blood loss too $(184 \pm 65$ vs $275 \pm 109 \mathrm{ml}$; $P=0.49)$.

The complication information was showed in Table 3. The overall incidence of complication is $48 \%(n=11)$. The incidence of pancreatic fistula was $39 \%(n=9)$. There was no statistical significance in the complication rate between the two groups (48 \%, $n=8$ vs $50 \%, n=3 ; P=0.90)$. All the patients were discharged within 30 days. There were four cases of grade IIIa complications. Two cases underwent percutaneous catheter drainage under the ultrasound scan. Two cases underwent ERCP to identify the pancreatic fistula. Three cases were diagnosed with spleen infarction. Twelve patients were not diagnosed with spleen infarction. Two patients did not take CT examination after surgery.

All the patients who suffered from spleen infarction underwent conservative treatment, and all were cured without splenectomy. The average length of stay (LOS) was $17 \pm 8$ days. There was no statistical significance between the spleen-preserving and spleen-resecting LDP groups $(18 \pm 8$ vs $15 \pm 7$ days; $P=0.36)$. The average dimension of the tumor was $32 \pm 12 \mathrm{~mm}$. The average number of lymph nodes that the specimen contained was $19.8 \pm 9.3$. There were 14 patients whose positive lymph node number is $\geq 1$. The pathology results were 18 cases of ductal adenocarcinoma, four cases of intraductal papillary mucinous adenocarcinoma, and one case of mucinous adenocarcinoma. The surgical margins of all the patients were negative. The final pathology results of the patients were as follows: two cases of IA stage (8.5\%), five cases of IB stage (22\%), two cases of IIA stage (8.5\%), 13 cases of IIB stage (57\%), and one case of III stage (4\%) (Table 4).

\section{Long-term prognosis}

The observation period was 5 years after surgery. The average survival duration was 19 months. The survival rates of 1,3 , and 5 years after surgery were 64.7, 52.9, and $41.2 \%$, respectively. Six patients suffered from local recurrence, one suffered from local recurrence combined with liver metastasis, and two suffered from retroperitoneal recurrence. The average time to recurrence was 14 months. The recurrence-free survival rates of 1, 3, and 5 years after surgery were 64.7, 47.1, and $35.3 \%$, respectively (Fig. 4).

\section{Discussion}

In recent studies $[14,15]$, the efficacy of radical en bloc LDP is satisfied for treatment of pancreatic cancer in long-term survival (5-year overall survival was $33 \%$ ). It is acceptable for treating pancreatic cancer. The data of our research was from a single center. The concept of en bloc LDP was based on R0 resection and adequate lymphadenectomy and ganglion resection.

Why do we preserve spleen? Adverse consequences have been observed after splenectomy. These include a greater likelihood of postoperative abscesses [16-18] and, most notably, a long-term risk of serious postsplenectomy sepsis. The risk of overwhelming postsplenectomy infection (OPSI) has been estimated to be 1 per 400-500 patient years and fatal OPSI to be 1 per $800-1000$ patient years $[19,20]$. While this risk is greatest in childhood, it persists to a lesser degree throughout life [21]. In addition, it increases the risk of later myocardial infarction, diabetes, and even cancer [22, 23].

How many types of spleen-preserving LDP surgery are in the world? There are mainly two types. One is invented by Kimura et al. [24] who performed spleenpreserving distal pancreatectomy with conservation of the splenic artery and vein. The advantage of this procedure was the low occurrence rate of spleen infarction. The disadvantage was isolating spleen vessels from the Toldt fascia which did not conform to the en 


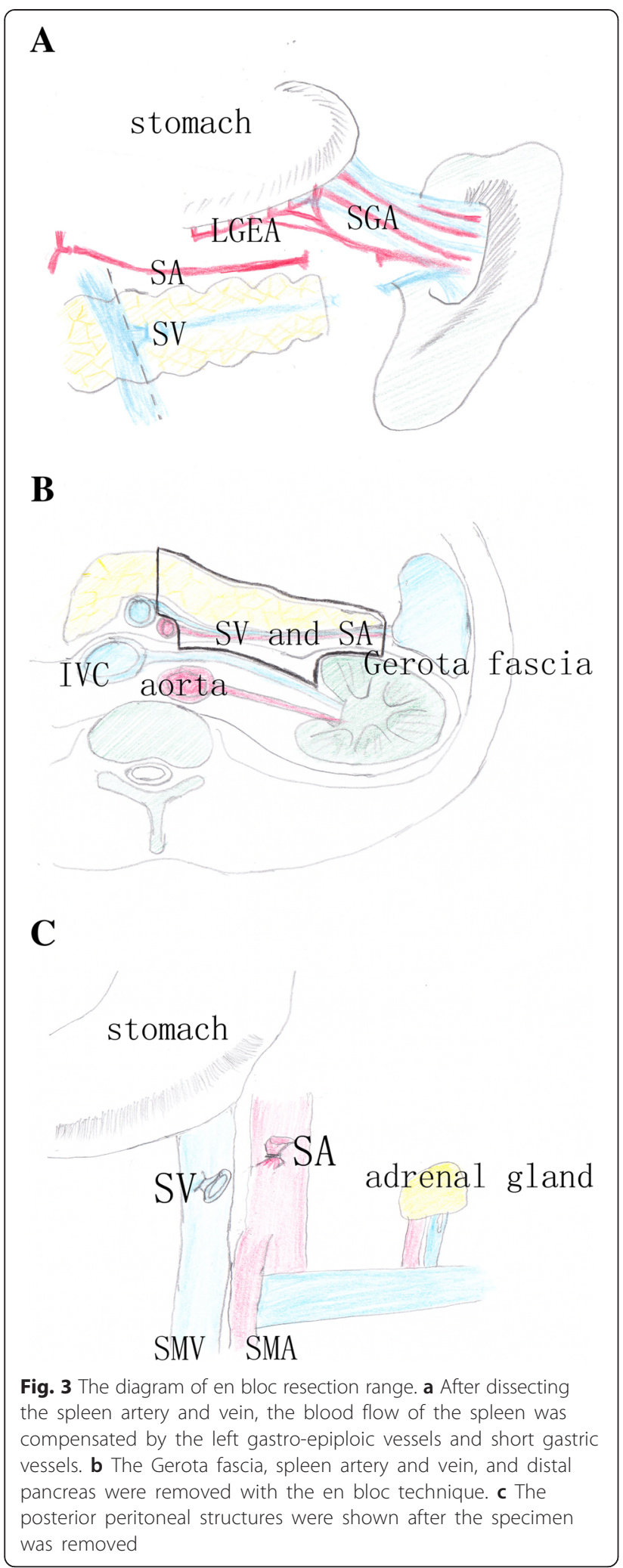

bloc standards; in other words, this procedure is difficult. The other procedure was invented by Warshaw [25] who performed spleen-preserving distal pancreatectomy with
Table 2 The information during the surgery

\begin{tabular}{ll}
\hline Number of cases & \\
En bloc spleen-preserving LDP & $17(74 \%)$ \\
En bloc spleen-resecting LDP & $6(26 \%)$ \\
Surgical time & $203 \pm 54 \mathrm{~min}$ \\
Blood loss & $208 \pm 264 \mathrm{ml}$ \\
Blood transfusion & 0 \\
Transfer to ODP & $1(4 \%)$ \\
\hline
\end{tabular}

resection of the splenic artery and vein. The blood flow of the spleen after surgery was compensated by the left gastro-epiploic vessels and short gastric vessels. Our procedure is similar with Warshaw's procedure except for more extensive retroperitoneal resection, lymphadenectomy, and celiac ganglion resection.

Our study compared with recent studies (Table 5) shows that the number of lymph nodes obtained by LDP was similar with that by ODP (19.8 vs 15.5$)$. One hundred percent R0 rate was our most satisfying outcome. The average dimension of the tumor was similar with that in ODP (32 vs $33.7 \mathrm{~mm}$ ) too.

The decrease of blood loss during surgery compared with ODP (208 vs $747 \mathrm{ml}$ ) was mainly due to amplification of the view and precise manipulation under the laparoscope as well as the increased abdominal pressure.

The en bloc LDP technique emphasizes resecting the Gerota fascia, Toldt fascia, and spleen vessels and distal

Table 3 The information after surgery

\begin{tabular}{ll}
\hline Clavien-Dindo complication degree & \\
Grade I or II & $7(30 \%)$ \\
Grade III or IV & $4(17 \%)$ \\
Pancreatic fistula degree & \\
Overall & $9(39 \%)$ \\
Grade A & $5(22 \%)$ \\
Grade B & $3(13 \%)$ \\
Grade C & $1(4 \%)$ \\
Operation method & \\
En bloc spleen-resecting LDP & $(n=17) 6(35 \%)$ \\
En bloc spleen-preserving LDP & $(n=6) 3(50 \%)$ \\
Pancreas partition method & \\
Harmonic scalpel ( $n=20)$ & $7(35 \%)$ \\
Ligasure ( $n=3)$ & $1(33 \%)$ \\
Spleen infarction & $3(18 \%)$ \\
Mortality rate & 0 \\
Length during stay (days) & $17 \pm 8$
\end{tabular}


Table 4 Pathology outcomes

\begin{tabular}{|c|c|}
\hline Variables & Value, $n(\%)$ or mean \pm SD \\
\hline \multicolumn{2}{|l|}{ Histologic factors } \\
\hline Tumor size (mm) & $32 \pm 12$ (range, $10-60)$ \\
\hline \multicolumn{2}{|l|}{ Final histologic diagnosis } \\
\hline Ductal adenocarcinoma & $18(79 \%)$ \\
\hline Adenocarcinoma associated with IPMC & $4(17 \%)$ \\
\hline Mucinous cystadenocarcinoma & $1(4 \%)$ \\
\hline \multicolumn{2}{|l|}{ Differentiation } \\
\hline Well & $11(48 \%)$ \\
\hline Others & $12(52 \%)$ \\
\hline Harvested LNs & $19.8 \pm 9.3$ (range, 5-40) \\
\hline Metastatic LNs & $2.0 \pm 4.1$ (range, $0-20)$ \\
\hline Surgical margin positive & 0 \\
\hline \multicolumn{2}{|l|}{ Stage of tumor (UICC classification) } \\
\hline pT1 & $3(13 \%)$ \\
\hline pT2 & $8(35 \%)$ \\
\hline pT3 & $11(48 \%)$ \\
\hline pT4 & $1(4 \%)$ \\
\hline pNO & 9 (39\%) \\
\hline $\mathrm{pN1}$ & $14(61 \%)$ \\
\hline \multicolumn{2}{|l|}{ p stage } \\
\hline IA & $2(8.5 \%)$ \\
\hline IB & $5(22 \%)$ \\
\hline$\| \mathrm{A}$ & $2(8.5 \%)$ \\
\hline$\| \mathrm{B}$ & $13(57 \%)$ \\
\hline III & $1(4 \%)$ \\
\hline
\end{tabular}

IPMC intraductal papillary mucinous carcinoma, LN lymph node, UICC Union for International Cancer Control classification, 7th edition pancreas as a whole to ensure the negative surgical margin. In contrast, in the standard ODP, it did not need to remove the Gerota fascia and Toldt fascia routinely. It is a controversial topic if we should preserve the spleen. Some study [26] showed that the incidence rate of spleen infarction was 11 to $29 \%$. Till now, there has not been any guideline support that LDP should be combined with splenectomy.

Distal pancreatic cancers sometimes invade to the lymph nodes and ganglion around the superior mesenteric artery. But, totally dissecting the nerve plexus around the SMA often results in intractable diarrhea and vomiting. So, we preserved part of the nerve plexus at the right side of the superior mesenteric artery while dissecting lymph nodes and ganglions as previously reported [27].

Kim et al. [26] reported that there was a low incidence rate of lymphatic metastasis at the hilus lienis. Preserving the spleen can avoid the decrease of immuno-ability and improve the oncological prognosis. All these reports [16-23] prompted us to preserve the spleen. Till now, there has not been any re-operate case because of hilus lienis lymphatic metastasis.

It was Mitchem et al. [10] who reported that the average LOS after ODP was $11 \pm 7$ days. Kooby et al. [7] reported that the LOS after LDP was $7 \pm 3$ days. Because of the different discharge criteria, LOS is difficult to compare. The main reason for prolonged LOS is complications (47 \%), such as pancreatic fistula (39\%). The optimized operative technique can reduce the incidence of complication. But, these techniques should also be summarized by a large number of cases of study.

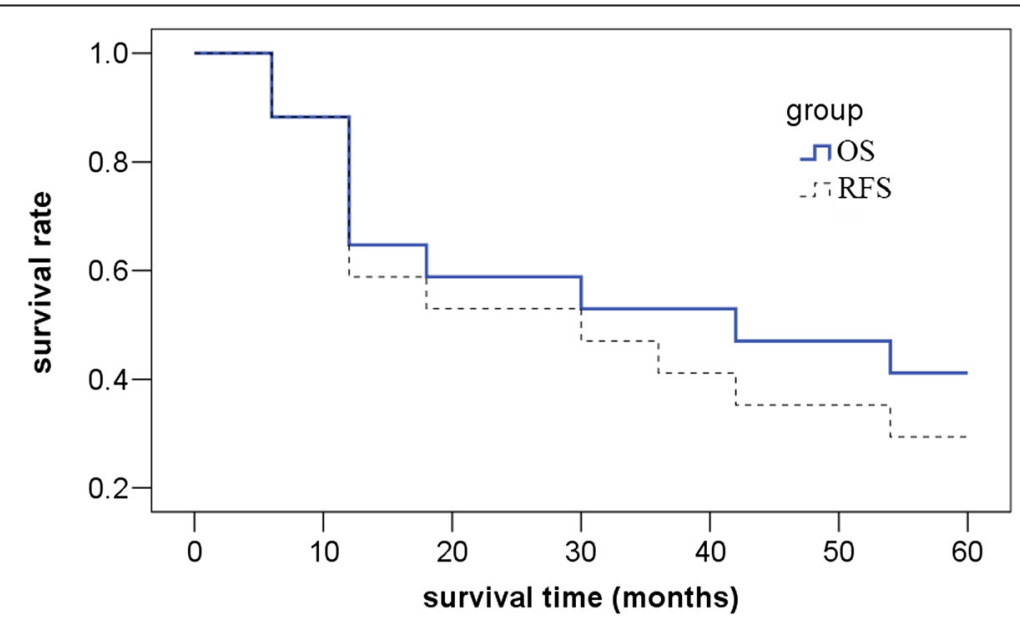

Fig. 4 The overall survival (OS) and recurrence-free survival (RFS) curve. The observation period was 5 years after surgery. The average survival duration was 19 months. The survival rates of 1,3, and 5 years after surgery were 64.7, 52.9, and $47.1 \%$, respectively. Six patients suffered from local recurrence, one suffered from local recurrence combined with liver metastasis, and two suffered from retroperitoneal recurrence. The average time to recurrence was 14 months. The recurrence-free survival rates of 1,3 , and 5 years after surgery were $58.8,47.1$, and $35.3 \%$, respectively 
Table 5 The prognosis reported by previous studies about ODP

\begin{tabular}{|c|c|c|c|c|c|c|c|}
\hline Source & Year & No. of cases & $\begin{array}{l}\text { Median survival } \\
\text { (months) }\end{array}$ & 5-year survival (\%) & $\begin{array}{l}\text { Mean no. of harvested } \\
\text { lymph nodes }\end{array}$ & $\begin{array}{l}\text { Mean tumor } \\
\text { size }(\mathrm{mm})\end{array}$ & $\begin{array}{l}\text { Mean blood } \\
\text { loss }(\mathrm{ml})\end{array}$ \\
\hline Shimada et al. [6] & 2006 & 88 & 22 & 19 & NS & NS & NS \\
\hline Kooby et al. [7] & 2010 & 189 & 16 & NS & 13 & 25 & 790 \\
\hline Yamamoto et al. [8] & 2010 & 73 & NS & 30 & NS & 33 & 707 \\
\hline Redmond et al. [9] & 2010 & 94 & 16 & NS & NS & 43 & NS \\
\hline Mitchem et al. [10] & 2012 & 47 & 26 & 36 & 18 & 34 & 744 \\
\hline
\end{tabular}

NS: not stated

In our study, the prognosis of en bloc spleen-preserving LDP was similar with the previous reports $[8,10$, $28,29]$. In these reports, the average overall survival (OS) was 13 to 26 months, and the 5-year survival rate was 19-36\%. Till now, based on the reports we searched, it is the first study about the long-term prognosis of standard en bloc spleen-preserving LDP. The limitations of our research were the character of the retrospective study and the only three types of pathology results. Randomized controlled trials, a large number of cases, and long-term trials can avoid these disadvantages. But because the incidence rate of distal pancreatic cancer is low, the study is hard to carry out.

Nevertheless, en bloc LDP preserving the spleen is safe and effective. The short-term and long-term prognoses are satisfied which supports this procedure as a treatment for distal pancreatic cancer.

\section{Conclusions}

The En-bloc spleen-preserving LDP surgery has good short-term and long-term outcomes for pancreatic cancers.

\section{Abbreviations}

DP: distal pancreatectomy; LDP: laparoscopic distal pancreatectomy; LOS: length of stay; ODP: open distal pancreatectomy; OS: overall survival; SMA: superior mesentery artery; SMV: superior mesentery vein.

\section{Competing interests}

The authors declare that they have no competing interests.

\section{Authors' contributions}

$\mathrm{ZS}$ and $\mathrm{YZ}$ contributed equally to this article. ZS performed design, material and data collecting, the statistical analysis, and drafted the manuscript. NZ participated in its design and coordination, $Y Z$ helped to draft the manuscript. All the authors read and approved the final manuscript.

\section{Funding}

The research was funded by the Beijing Municipal Administration of Hospitals Clinical Medicine Development of Special Funding Support, code XMLX201309, and Japan-China Sasakawa Medical Fellowship. We thank the foundation and all the patients studied in this project.

Received: 15 July 2015 Accepted: 12 November 2015

Published online: 25 November 2015

\section{References}

1. Merkow J, Paniccia A, Edil BH. Laparoscopic pancreaticoduodenectomy: a descriptive and comparative review. Chin J Cancer Res. 2015;27(4):368-75.

2. Postlewait LM, Kooby DA. Laparoscopic distal pancreatectomy for adenocarcinoma: safe and reasonable? J Gastrointest Oncol. 2015;6(4):406-17.

3. Sahakyan MA, Kazaryan AM, Rawashdeh M, Fuks D, Shmavonyan M, Haugvik SP, et al. Laparoscopic distal pancreatectomy for pancreatic ductal adenocarcinoma: results of a multicenter cohort study on 196 patients. Surg Endosc. 2015. Epub ahead of print.

4. de Rooij T, Sitarz R, Busch OR, Besselink MG, Abu HM. Technical aspects of laparoscopic distal pancreatectomy for benign and malignant disease: review of the literature. Gastroenterol Res Pract. 2015:2015:472906.

5. Saisho $H$, Yamaguchi $T$. The general rules for the study of pancreatic cancer from the viewpoint of internal medicine. Nihon Geka Gakkai zasshi. 2000; 101(2):228-32

6. Shimada K, Sakamoto Y, Sano T, Kosuge T. Prognostic factors after distal pancreatectomy with extended lymphadenectomy for invasive pancreatic adenocarcinoma of the body and tail. Surgery. 2006;139(3):288-95.

7. Kooby DA, Gillespie T, Bentrem D, Nakeeb A, Schmidt MC, Merchant NB, et al. Left-sided pancreatectomy: a multicenter comparison of laparoscopic and open approaches. Ann Surg. 2008;248(3):438-46.

8. Yamamoto J, Saiura A, Koga R, Seki M, Katori M, Kato Y, et al. Improved survival of left-sided pancreas cancer after surgery. Jpn J Clin Oncol. 2010;40(6):530-6.

9. Redmond KJ, Wolfgang CL, Sugar EA, Ahn J, Nathan H, Laheru D, et al. Adjuvant chemoradiation therapy for adenocarcinoma of the distal pancreas. Ann Surg Oncol. 2010;17(12):3112-9.

10. Mitchem JB, Hamilton N, Gao F, Hawkins WG, Linehan DC, Strasberg SM. Long-term results of resection of adenocarcinoma of the body and tail of the pancreas using radical antegrade modular pancreatosplenectomy procedure. J Am Coll Surg. 2012;214(1):46-52.

11. Clavien PA, Barkun J, de Oliveira ML, Vauthey JN, Dindo D, Schulick RD, et al. The Clavien-Dindo classification of surgical complications: five-year experience. Ann Surg. 2009;250(2):187-96.

12. Bassi C, Dervenis C, Butturini G, Fingerhut A, Yeo C, Izbicki J, et al. Postoperative pancreatic fistula: an international study group (ISGPF) definition. Surgery. 2005;138(1):8-13.

13. Tempero MA, Malafa MP, Behrman SW, Benson 3rd AB, Casper ES, Chiorean EG, et al. Pancreatic adenocarcinoma, version 2.2014: featured updates to the NCCN guidelines. J Natl Compr Canc Netw. 2014;12(8):1083-93.

14. Ham H, Kim SG, Kwon HJ, Ha H, Choi YY. Distal pancreatectomy with celiac axis resection for pancreatic body and tail cancer invading celiac axis. Ann Surg Treat Res. 2015;89(4):167-75.

15. Okada K, Kawai M, Tani M, Hirono S, Miyazawa M, Shimizu A, et al. Surgical strategy for patients with pancreatic body/tail carcinoma: who should undergo distal pancreatectomy with en-bloc celiac axis resection? Surgery. 2013;153(3):365-72.

16. Shoup M, Brennan MF, McWhite K, Leung DH, Klimstra D, Conlon KC. The value of splenic preservation with distal pancreatectomy. Arch Surg. 2002;137(2):164-8

17. Sperti C, Beltrame V, Bellamio B, Pasquali C. Spleen-preserving distal pancreatectomy with splenic vessels excision. Surgery. 2012;152(1):140-1.

18. Miura F, Sano K, Amano H, Toyota N, Wada K, Kadowaki S, et al. Is spleenpreserving distal pancreatectomy with excision of the splenic artery and vein feasible? Surgery. 2011;150(3):572. 
19. Adriani KS, Brouwer MC, van der Ende A, van de Beek D. Bacterial meningitis in adults after splenectomy and hyposplenic states. Mayo Clin Proc. 2013;88(6):571-8.

20. Morgan TL, Tomich EB. Overwhelming post-splenectomy infection (OPSI): a case report and review of the literature. J Emerg Med. 2012;43(4):758-63.

21. Sheng CF, Liu BY, Zhang HM, Zheng X. Overwhelming postsplenectomy infection. Genet Mol Res. 2015;14(1):2702-6.

22. Xu JL, Tang CW, Feng WM, Bao Y. Hematological benefits after spleenpreserving distal pancreatectomy: perioperative and long-term outcome analysis. Hepatogastroenterology. 2013;60(128):2103-6.

23. Mori Gonzales E, Celis J, Ruiz E, Payet E, Berrospi F, Chavez I, et al. Impact of splenectomy and/or distal pancreatectomy in the prognosis of the proximal gastric cancer. Rev Gastroenterol Peru. 2012;32(1):32-43.

24. Kimura W, Yano M, Sugawara S, Okazaki S, Sato T, Moriya T, et al. Spleenpreserving distal pancreatectomy with conservation of the splenic artery and vein: techniques and its significance. J Hepatobiliary Pancreat Sci. 2010;17(6):813-23.

25. Warshaw AL. Distal pancreatectomy with preservation of the spleen. J Hepatobiliary Pancreat Sci. 2010;17(6):808-12.

26. Kim SH, Kang CM, Satoi S, Sho M, Nakamura Y, Lee WJ. Proposal for splenectomy-omitting radical distal pancreatectomy in well-selected leftsided pancreatic cancer: multicenter survey study. J Hepatobiliary Pancreat Sci. 2013;20(3):375-81.

27. Kawabata A, Hamanaka Y, Suzuki T. Potentiality of dissection of the lymph nodes with preservation of the nerve plexus around the superior mesenteric artery. Hepatogastroenterology. 1998;45(19):236-41.

28. Howard TJ, Krug JE, Yu J, Zyromski NJ, Schmidt CM, Jacobson LE, et al. A margin-negative $\mathrm{R} 0$ resection accomplished with minimal postoperative complications is the surgeon's contribution to long-term survival in pancreatic cancer. J Gastrointest Surg. 2006;10(10):1338-45. discussion 45-6.

29. Kang CM, Kim DH, Lee WJ. Ten years of experience with resection of leftsided pancreatic ductal adenocarcinoma: evolution and initial experience to a laparoscopic approach. Surg Endosc. 2010;24(7):1533-41.

\section{Submit your next manuscript to BioMed Central and take full advantage of:}

- Convenient online submission

- Thorough peer review

- No space constraints or color figure charges

- Immediate publication on acceptance

- Inclusion in PubMed, CAS, Scopus and Google Scholar

- Research which is freely available for redistribution 